\section{Comunidad de aprendizaje en línea: Bioética en el grado de la Universidad}

\section{Moos, A}

Facultad de Ciencias Médicas (FCM) - Universidad Nacional de Córdoba (UNC), Argentina. E-mail: amoos@fcm.unc.edu.ar

Fernández de Ullivarri, L

Facultad de Ciencias Médicas - Universidad Nacional de Córdoba, Argentina

PALAVRAS-CHAVE: bioética, aprendizaje en línea, universidad.

Introducción: La UNC desde 2011 implementa el Programa de Base de Estudios sobre Bioética-PBEB, Memorándum de Entendimiento firmado con UNESCO en 2011 y renovado en 2018. Un objetivo contenido en la propuesta académica (PA) es que los estudiantes sean capaces de determinar los problemas éticos en la práctica profesional justificando sus decisiones. Se reconoce el aporte de la Bioética en procesos de toma de decisión, ofreciendo espacios plurales, deliberativos y democráticos ${ }^{1}$. Participan de la PA estudiantes de grado de la FCM. Presenta una modalidad mixta, encuentros presenciales-EP, y no presenciales en aula virtual-Plataforma de Gestión del Aprendizaje Moodle (PGAM) que permite trabajar en comunidades de aprendizaje en línea. Algunas ventajas académicas del entorno virtual son que crea un medio de comunicación fluido, permite interactividad, asincronismo, foros de debate $e^{2-3-4}$. Método: La selección de herramientas corresponde a los objetivos pedagógicos. Se utilizan recursos (documentos, imágenes, videos, páginas webs) y actividades de aprendizaje (foros, tareas, cuestionarios). Se describe la actividad foro en cuatro formatos que permiten a los estudiantes participar con diferentes modalidades. Resultados: Foros: -"Debate sencillo": intercambio de ideas sobre un tema propuesto, todo en una página. Útil para debates cortos y concretos. Ejemplo “ ¿Nos conocemos?: los participantes se conocen (nombre-residencia-carrera/año de cursado-actividades ocio) en un ámbito cálido y amigable de aprendizaje, dónde se sienten cómodos y estimulados para la conversación, integrando a estudiantes de diferentes carreras-provinciaspaíses. - "Cada estudiante plantea un tema": cada estudiante empieza una discusión. Útil antes o luego del EP. Ejemplo ¿Qué ves?: complementado con un video, se utiliza para conocer la opinión de los estudiantes, con preguntas disparadoras ¿Qué les produce (sentimientos) el video?, ¿Qué temas aborda?, ¿Cuáles son los actores que identifican?, ¿Qué análisis pueden aportar? Permite proponer un nuevo debate con temas no abordados, Favorece la reflexión, participación e intercambio de las diferentes miradas de los temas. - "Pregunta y Respuestas": se responde una consigna, primero deben fijar sus puntos de vista antes de ver los mensajes del resto. Útil para iniciar un tema diagnóstico y hacer el anclaje con conocimientos previos y/o para expresar un punto de vista sobre un tema. Estimula la participación sin condicionamiento ni influenciada por la mirada externa. Ejemplo: Gramática superficial y gramática profunda del PBEB-Unidad 1. -"Estándar formato de Blog”: cualquiera puede iniciar un nuevo debate. Los temas se muestran en una página con enlaces "Discute este tema". Ejemplo: Nuestra producción: los estudiantes elaboran una producción que comparten, todos envían mensajes con consultas y/o sugerencias a las diferentes producciones. Muestra una estética diferente, promueve un rol activo en la producción propia y en las de sus compañeros. En las evaluaciones los estudiantes destacan el aprendizaje en línea, mencionando a los foros que estimulan la participación y trabajo interactivo. Conclusiones: Es significativo el potencial que ofrece la PGAM para la PA, su adecuada utilización articulada con los EP contribuye a la formación en Bioética en el grado. Es una herramienta útil, contribuye al logro de los objetivos, brinda otra oportunidad para la deliberación, construcción de consensos en estructuras deliberativas.

AGRADECIMENTOS: Por el asesoramiento y acompañamiento en la implementación: Mgter. Susana Vidal, Esp. Programa. Prog. para ALyC de Bioética y Ética de la Ciencia Prog.de Filosofía Sector de Ciencias Sociales y Humanas de la UNESCO, Oficina Regional de Ciencias para ALyC. Montevideo, Uruguay; Lic. Karina Compta, responsable de aulas Moodle, Sec. de Informática-FCMUNC.

\section{REFERÊNCIAS}

[1] S. VIDAL. Nuevas y viejas preguntas en la educacion en bioética. En Vidal S. (Editora). La Educación en Bioética en América Latina y el Caribe: Experiencias realizadas y desafíos futuros. UNESCO, Oficina Regional de Ciencia de la UNESCO Montevideo (2012), pp. 15-35.

[2] A. SAORÍN, Moodle 2.0. Manual del profesor (2012). Disponible

en

https://docs.moodle.org/all/es/Manuales de Moodle

[3] E. BARBERÁ, A. BADÍA. Educar con aulas virtuales: Orientaciones para la innovación en el proceso de enseñanza y aprendizaje. Antonio Machado Libros S.A. Madrid (2004). [4] M. DELGADO FERNÁNDEZ, A. SOLANO GONZÁLEZ. Estrategias didácticas creativas en entornos virtuales para el aprendizaje. Rev. Elect. Actualidades Investigativas en Educación, vol. 9, núm. 2 (2009), pp. 1-21. 